\title{
Alterations of lung structure in experimental diabetes, and diabetes associated with hyperlipidaemia in hamsters
}

\author{
D. Popov, M. Simionescu
}

Alterations of lung structure in experimental diabetes, and diabetes associated with hyperlipidaemia in hamsters. D. Popov, M. Simionescu. CERS Journals Ltd 1997.

ABSTRACT: Since hyperglycaemia is known to affect normal pulmonary physiology and biochemistry and few structure-function correlations have been reported, we designed experiments on hamsters subjected to streptozotocin-induced diabetes or diabetes associated with hyperlipidaemia, and investigated the impact of these conditions on the lung structure.

At time intervals ranging 2-24 weeks from the inception of disease (without correcting blood glucose with insulin), the animals were sacrificed, and plasma glucose and cholesterol assayed. The lung was processed for electron microscopy, and the structural changes of the capillary and venular endothelium, of epithelial cells, and interstitium were examined.

In diabetic animals, especially after 6 weeks of disease, a gradual narrowing of $\sim 35 \%$ of the capillaries and $\mathbf{3 0 \%}$ of the alveoli, and hyperplasia of the extracellular matrix, rich in collagen bundles, were observed. Frequently, capillaries contained adherent intravascular macrophages suggestive of an inflammatory process. The capillary endothelium was characterized by numerous plasmalemmal vesicles, often fused, well-developed synthesizing apparatus (endoplasmic reticulum and Golgi complex) and cytoskeleton, and an uneven distribution of the anionic sites on the luminal plasmalemma. The venular endothelium was particularly rich in Weibel-Palade bodies. The alveolar epithelium was often collapsed, compressing surfactant within the airspace. The lung interstitium was apparently enlarged, and the fibroblasts and contractile interstitial cells frequently contained lipid droplets. These alterations were more pronounced and occurred at a faster rate (4 weeks) in diabetes associated with hyperlipidaemia.

The structural modifications reported in this study support the functional disturbances observed in association with hyperglycaemia, sustaining the conclusion that the lung is an organ affected by diabetes.

Eur Respir J 1997; 10: 1850-1858.

Institute of Cellular Biology and Pathology "Nicolae Simionescu", Bucharest, Romania

Correspondence: D. Popov

Institute of Cellular Biology and Pathology

"Nicolae Simionescu"

8 B.P. Hasdeu Street

79691 - Bucharest

Romania

\section{Keywords: Diabetes}

endothelium

epithelial cells

hyperlipidaemia

lung

Received: November 251996

Accepted after revision April 141997

This study was supported by the Romanian Academy and by USA-NIH Fogarty International Research Collaboration Award TW00118.
The impact of diabetes on the pulmonary system has so far been documented mainly by mild functional abnormalities, such as a reduction in elastic recoil, lung volumes, and pulmonary diffusing capacity [1]. Diabetic patients show alterations of the outcome of pulmonary function tests, such as a reduced forced vital capacity and forced expiratory volume in one second [2]. Recently, the pulmonary venous resistance was found to be selectively increased 2 weeks after the induction of experimental diabetes [3].

The changes in lung biochemistry occurring in diabetes consisted in: suppression of aniline p-hydroxylase activity [4]; a diminished level of insulin-like growth factor-I (IGF-I) [5]; elevated activity of angiotensin-converting enzyme (ACE) [6]; and increased susceptibility to glycation of lung proteins [7]. The only structural modification described, so far, is the thickening of the alveolar basement membranes in human diabetic lungs [8], and in rats with streptozotocin-induced diabetes [9]. The cause of the thickening and duplication of basement membranes in diabetes is still not well understood
[10]. Recently, a specific type of nodular fibrosis of the lung was described in diabetes [11].

In addition, a delayed expression of surfactant protein A (SP-A) was reported, as well as of hydrophobic surfactant protein (SP-B, SP-C) in foetuses of streptozotocin-treated rats $[12,13]$, and an increased muscularization of the pulmonary arteries of infants of diabetic mothers, contributing to pulmonary hypertension [14]. An increased susceptibility to specific pulmonary infections was also described for diabetics $[15,16]$.

Knowledge of the influence of hyperlipidaemia on the pulmonary system comes from a few early studies on experimental pulmonary atherosclerosis [17-19]. More recently, increased levels of cholesterol content in the lungs [20], systemic induction of 15-lipoxygenase activity [21], and massive accumulation of foam cells in the intima of lung muscular arteries during pulmonary atherogenesis [22] were reported.

Since no correlation exists between these functional abnormalities and the alterations of the lung structure in diabetes, we designed experiments to examine the 
effect of streptozotocin-induced diabetes and diabetes associated with hyperlipidaemia (which frequently occur concurrently) on the ultrastructural components of the lung, and discuss the consequences of these alterations on lung physiology.

\section{Materials and methods}

\section{Animals}

Sixty male golden Syrian hamsters, 3-4 months old, were maintained in standard housing conditions, on a $14 \mathrm{~h} / 10 \mathrm{~h}$ light/dark cycle, and provided with rodent chow and water ad libitum. The experiments were performed in accordance with "Principles of Laboratory Animal Care" (NIH publication No. 83-25, revised 1985).

\section{Experimental protocol}

The hamsters were divided into three groups: 1) diabetics (D), injected i.p. with streptozotocin (Sz) (50 $\mathrm{mg} \cdot \mathrm{kg}^{-1}$ body weight (BW)), dissolved in $0.1 \mathrm{M}$ citrate buffer, $\mathrm{pH} 4.5 ; 2)$ simultaneously diabetics and hyperlipidaemics (HD), injected with $\mathrm{Sz}$ (as above) and fed a pelleted chow supplemented with $3 \%$ cholesterol and $15 \%$ buffer; and 3) controls (C), untreated age-matched animals injected with vehicle only. The body weight of the hamsters, and the evolution of plasma glucose and cholesterol were monitored every 2 weeks, for 24 weeks from the beginning of the experiment. No insulin treatment was used to correct blood glucose concentrations in the D and HD groups.

\section{Plasma assays}

Under light anaesthesia, blood was collected on $2.7 \mathrm{mM}$ ethylenediamine tetra-acetic acid (EDTA) $\left(1 \mathrm{mg} \cdot \mathrm{mL}^{-1}\right.$ blood), either from the venous orbital plexus of fasted animals, or from the abdominal aorta at the time of sacrifice. Plasma was separated, and glucose and cholesterol concentrations determined by enzymatic kits (Sigma, St. Louis, MO, USA), according to the instructions supplied.

\section{Electron microscopy}

At regular time intervals (2-24 weeks) after the initiation of the experiment, animals that showed significant loss in body weight and elevated plasma glucose and/or cholesterol were selected for examination. Hamsters were anaesthesized by an i.p. injection of 5\% chloral hydrate $\left(0.1 \mathrm{~mL} \cdot 100 \mathrm{~g}^{-1} \mathrm{BW}\right)$, and after laparotomy and catheterization of the abdominal aorta, the vasculature was perfused with phosphate-buffered saline (PBS) at a constant flow rate of $6 \mathrm{~mL} \cdot \mathrm{min}^{-1}$. The vena cava abdominalis was used as the outlet. The hamsters were breathing during PBS perfusion, and the airspaces were not artificially inflated. Through the same route, the tissues were fixed in situ with a mixture of paraformaldehyde $(2.5 \%)$, glutaraldehyde $(1.5 \%)$ supplemented with $\mathrm{CaCl}_{2}(2.5 \mathrm{mM})$ in $\mathrm{HCl}-\mathrm{Na}$ cacodylate buffer $(0.1 \mathrm{M}$,
$\mathrm{pH}$ 7.4). After $10 \mathrm{~min}$ of vascular perfusion, small fragments of the lung left lobe were excised, and further fixed in the same fixative $(90 \mathrm{~min})$, followed by $1 \%$ osmium tetroxide $\left(\mathrm{OsO}_{4}\right)$ in the same buffer (90 min), stained in block with uranyl acetate, dehydrated in graded ethanols, and embedded in Epon 812. Thin sections stained with uranyl acetate $(7.6 \%$, dissolved in doubledistilled water) and lead citrate $(0.4 \%$ in $0.1 \mathrm{~N} \mathrm{NaOH})$ were examined with an electron microscope (201C; Philips, Eindhoven, The Netherlands).

\section{Detection of endothelial anionic sites}

For this purpose, after washing-out the blood, cationized ferritin $(\mathrm{CF}), 1 \mathrm{mg} \cdot \mathrm{mL}^{-1}$, in PBS was perfused for 2 min through the entire vasculature. Afterwards, the standard protocol described above for electron microscopy was used.

\section{Morphometric analysis}

These assays were performed to quantify: 1) the percentage of collapsed capillaries and/or alveoli, using feature counting on $\sim 150$ micrographs at $\times 15,000$ magnification, and displaying 5-7 capillaries per electronmicrograph; 2) the thickening of the fused basal laminae between endothelium and type I epithelial cells, evaluated on $\sim 100$ electronmicrographs at $\times 55,000$ magnification, using the minimum thickness method of WiLliamson et al. [23]. The latter implies measurements of the thickness of the capillary basement membrane at two points where the basement membrane is thinnest. The points selected must be at least $1 \mathrm{~cm}$ apart as measured on electronmicrograph, and must not overlie pericytes.

\section{Results}

\section{Body weight and plasma modifications}

Control hamsters $(C)$. The body weight of normal hamsters was $93 \pm 10 \mathrm{~g}$ during the 24 weeks of the experiment; the plasma glucose and cholesterol concentrations were $100 \pm 44$ and $79.3 \pm 17.3 \mathrm{mg} \cdot \mathrm{dL}^{-1}$, respectively, throughout the experimental period.

Diabetic animals $(D)$. Body weight, as an overall index of metabolic disturbance, was lower in the diabetic hamsters $(55 \pm 5 \mathrm{~g})$ as compared with that of age-matched controls. An elevated plasma glucose concentration, up to $440 \pm 20 \mathrm{mg} \cdot \mathrm{dL}^{-1}$ was detected. As reported for diabetes [24], the heart showed conspicuous myocardial hypertrophy, with thickening of the left ventricular wall and interventricular septum.

Diabetic and hyperlipidaemic hamsters $(H D)$. The hamsters subjected simultaneously to diabetes and hyperlipidaemia exhibited essentially similar changes in terms of body weight and glycaemia as those in the diabetic group, but at a faster rate [24]. In addition, in HD animals, the plasma cholesterol increased steadily during the experiment, and attained the highest values $(900 \pm 100$ $\left.\mathrm{mg} \cdot \mathrm{dL}^{-1}\right)$ after 24 weeks of combined disease. 
Pathomorphological alterations of the lung in diabetic hamsters

The pathological changes of the lung structure occurred gradually, but were particularly evident after 6 weeks of hyperglycaemia. After that, the modifications observed developed into more advanced changes of the endothelia (of capillaries and venules), epithelia, and interstitium, leading at 18 and 24 weeks of disease to a generally altered structure of the diabetic lung.

Lung capillaries. At the beginning of the experimental period, lung capillaries had a round contour and generally normal structure. Progressively, but particularly after 6 weeks of diabetes, the structure of the capillary endothelial cells was altered. The cytoplasm displayed an abundant biosynthesizing apparatus (endoplasmic reticulum and Golgi complex), organelles involved in degradation (multivesicular bodies and lysosomes), a large number of plasmalemmal vesicles (caveolae) often fused, and a relatively well-developed cytoskeleton (microfilaments and microtubules) within an apparently enlarged endothelial cell (fig. 1a). Sometimes, the endothelial plasmalemma displayed irregularities that protruded into the capillary lumen (fig. 1b).

In hyperglycaemic animals, exposure of the lung vasculature to cationized ferritin (CF), led to a patchy decoration of endothelial plasmalemma. As shown in figure $1 \mathrm{~b}$, the CF-detectable anionic-sites appeared clustered over small areas of the luminal membrane, leaving large zones devoid of CF-decoration. This was in contrast to the aspect of capillaries in normal animals, where the $\mathrm{CF}$-decorated anionic sites had a homogeneous distribution over the endothelial luminal plasmalemma (fig. $1 b$, inset).

Within the capillary lumen, intravascular macrophages were often found adhering to the endothelium (fig. 2a).

At 18 and 24 weeks of hyperglycaemia, morphometric analysis indicated that $\sim 35 \%$ of the capillaries and $\sim 30 \%$ of the alveoli had become narrowed or even partially collapsed structures (fig. 2b and c). Morphometric analysis indicated that, progressively, during the 6th to 24th weeks of the experiment, an increase of up to fourfold (above control) had occurred in the thickening of the fused endothelial and epithelial basal laminae (fig. $2 \mathrm{~d})$. The enlargement of the basal laminae and pericapillary interstitium occurred focally, but was distributed throughout the microvasculature.

Lung venules. In diabetes, the venular endothelium showed numerous features in common with the capillary endothelium, such as frequent plasmalemmal vesicles, sometimes fused, well-developed synthesizing apparatus and lysosomes, and a patchy and scarce decoration of the plasmalemma with CF-detectable anionic sites (fig. 3). The most striking feature of the venular endothelium in diabetes consisted in the abundance of WeibelPalade bodies (fig. 3).

Alveolar epithelium. Type I epithelial cells presented no evident structural changes, except for some apparently enlarged intercellular junctions (fig. 2d). As already mentioned, the basal lamina interposed between these cells and the capillary endothelial cells was thickened ( fourfold), a feature that may impede the normal air-blood barrier function. In addition, starting with 6 weeks of diabetes, frequent focal enlargements (nodules) of extracellular matrix were observed beneath the type I epithelial cells (fig. 2a, inset, and $2 \mathrm{~d}$ ).

Type II epithelial cells appeared structurally normal. As in the case of type I cells, the underlying extracellular matrix was hyperplasic and apparently enriched in collagen bundles and elastin.

Interstitium. Starting 6 weeks into the experiment, the connective tissue cell components, such as fibroblasts and contractile interstitial cells, often contained numerous lipid droplets (figs. 2b and 4b). Also, the matrix fibres (collagen and elastin) were apparently more abundant than in normal lung (figs. $1 \mathrm{~b}$ and $4 \mathrm{a}$ ). This increase in extracellular matrix could contribute to the narrowing of capillaries, as well as to the enlargement (in some areas) of blood and airspaces (fig. 4a). Often, within the reduced alveolar space, the tubular myelin and surfactant were compressed (fig. 5).

Alveolar macrophages. These cells displayed an apparently normal structure except that, at 24 weeks of hyperglycaemia, cholesterol crystals were often detected in the cytoplasm.

\section{Alterations of the lung in combined diabetes and hyper- lipidaemia}

In HD hamsters, the alterations of the lung cells and interstitium were similar to those described for diabetic animals, except that they appeared at a faster rate, i.e. at 3-4 weeks of combined hyperglycaemia and hyperlipidaemia rather than at 6 weeks, as found for diabetic animals. Thus, the capillary endothelial cells of HD hamsters showed: overexpression of the biosynthesizing machinery; a gradual but constant reduction in density of decoration of the luminal plasmalemma with CFdetectable anionic sites; thickening of the basal lamina; and focal enlargement of the pericapillary matrix. Figure 6 shows an example of lung structure in an HD animal at 18 weeks of combined disease; the characteristic narrowing of the alveolar space, and the apparently enlarged interstitium containing elastin, collagen bundles, and numerous lipid-loaded interstitial cells were often observed.

\section{Discussion}

The results obtained in this study indicate that, in hamsters (not treated with insulin), diabetes induces several pathomorphological modifications of the lung, such as: changes the capillary and venular endothelium; hyperplasia of the basal lamina and extracellular matrix; and enlargement of the interstitium, within which lipidloaded interstitial cells occurred. These alterations are more prominent and occur at a faster rate in hamsters subjected to the combined effect of hyperglycaemia and hyperlipidaemia. These results are in good agreement with 


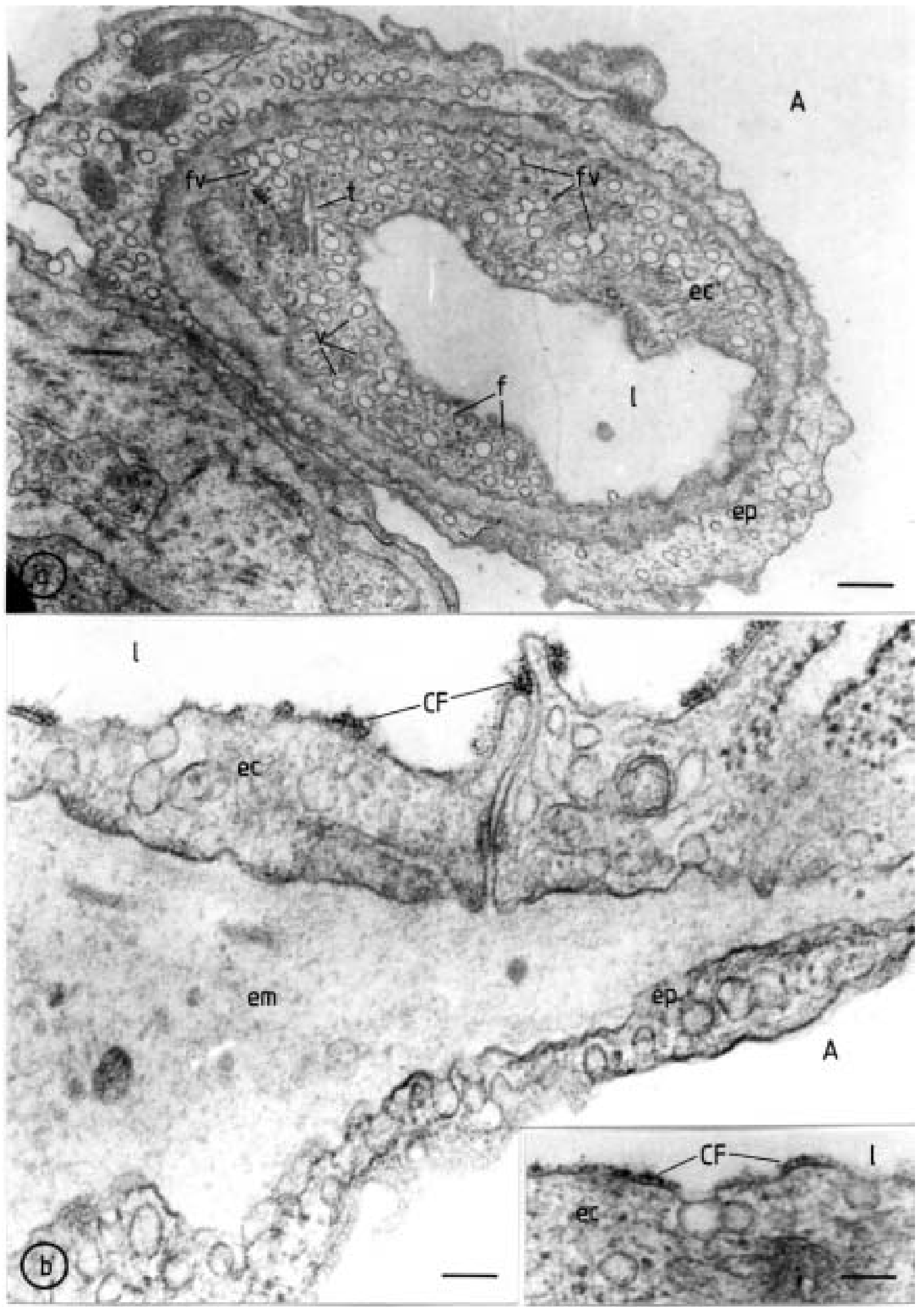

Fig. 1. - Lung capillary of a 6 week old diabetic hamster. a) The partially collapsed capillary is surrounded by endothelial cells (ec) apparently expanded, containing a large number of plasmalemmal vesicles (v), some of them fused (fv), microfilaments (f) and microtubules (t). (Internal scale bar $=0.290 \mu \mathrm{m}$ ). b) Anionic sites of the endothelial luminal plasmalemma, detected by perfusion in situ of cationized ferritin (CF), are unevenly distributed, as indicated by the patchy CF-labelling as opposed to even CF-decoration of normal (control) hamsters (inset). Note the enlarged extracellular matrix (em) present between endothelial cell (ec) and type I epithelial cell (ep). (Internal scale bar=0.120 $\mu \mathrm{m}$; and for inset=0.160 nm). 1: capillary lumen; A: alveolar space. 


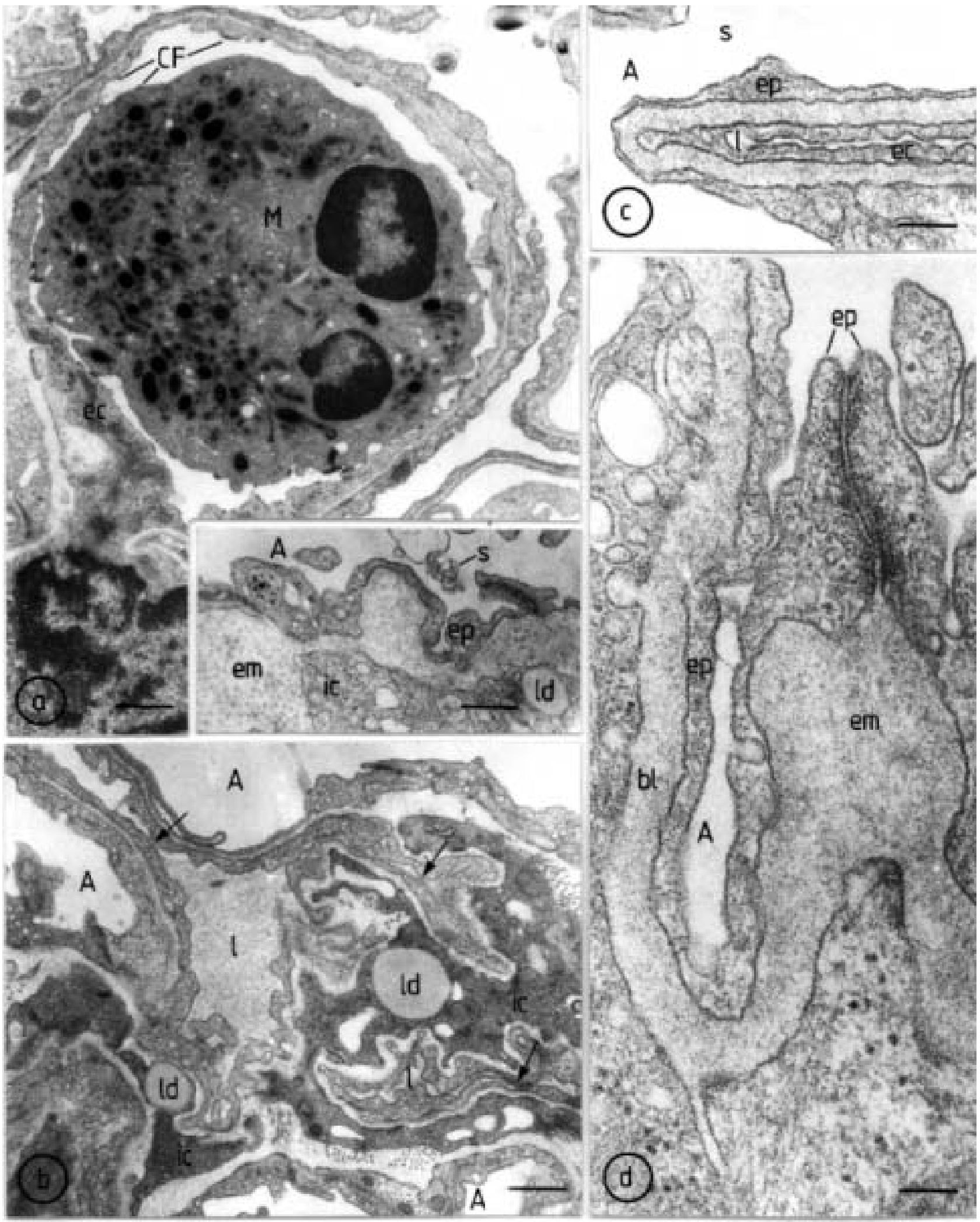

Fig. 2. - Modification of the structure of the lung of a 24 week old diabetic hamster. a) Some capillaries are characterized by the presence of intravascular macrophages (M) presenting areas closely adherent to the lining endothelial cell (ec). (Internal scale bar $=0.770 \mu \mathrm{m}$; and for inset $=0.200 \mu \mathrm{m}$ ). b) Narrowing of the capillary lumen (1) leads, in some areas, to capillary occlusion (arrows) that even after perfusion retains the plasma in the vascular space. Contractile interstitial cells (ic) contain cytoplasmic lipid droplets (ld). (Internal scale bar=0.640 $\mu \mathrm{m}$ ). c) The avesicular zone of a collapsed capillary. (Internal scale bar=0.200 $\mu \mathrm{m}$ ). d) Focally expanded extracellular matrix (em) often underlies type I epithelial cells. (Internal scale bar=0.140 $\mu \mathrm{m}$ ). CF: cationized ferritin; A: alveolar space; s: surfactant; bl: basal lamina; ep: type I epithelial cells. 


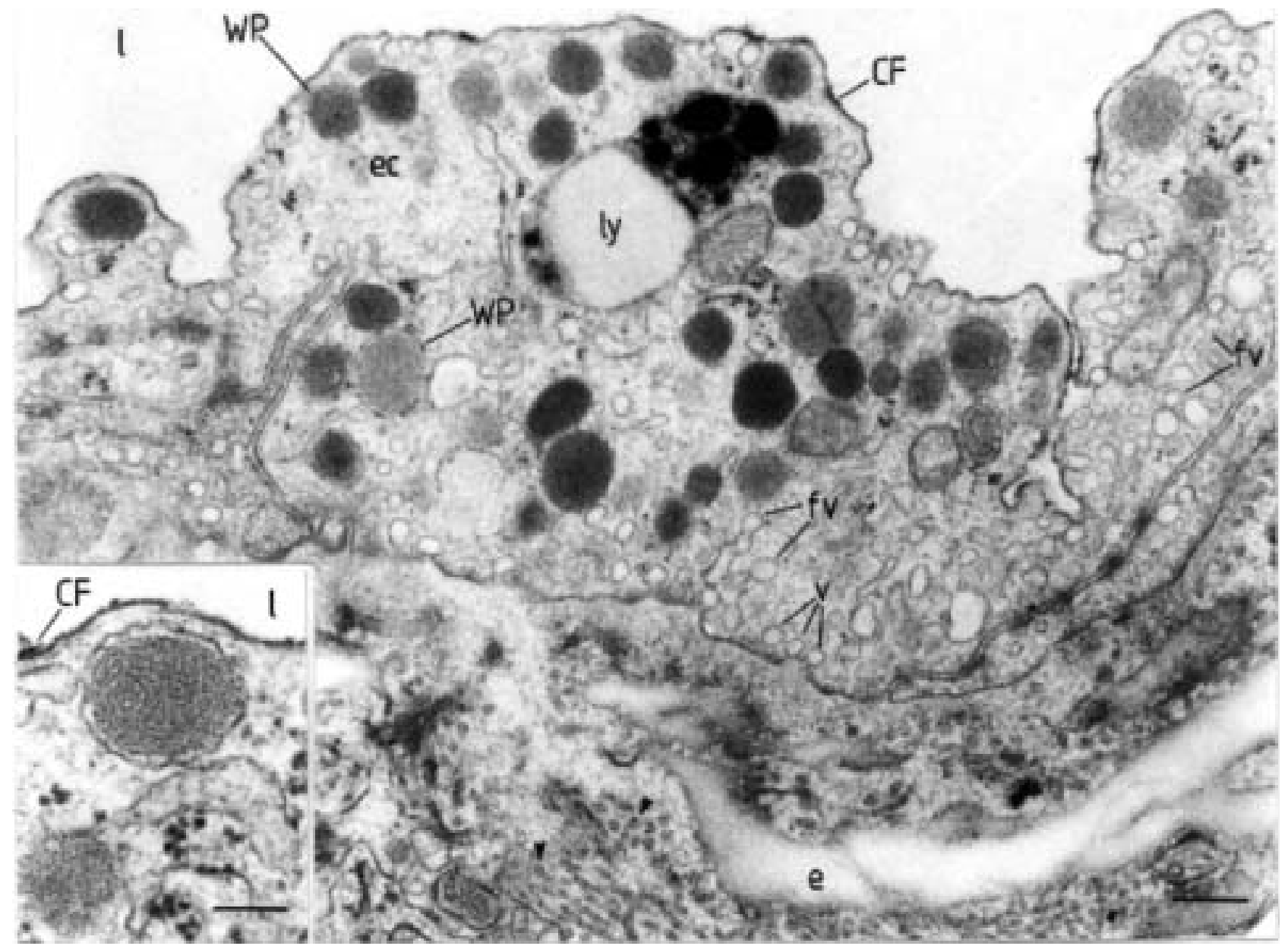

Fig. 3. - Lung venular endothelium of a 6 week old diabetic hamster perfused in situ with cationized ferritin (CF). The endothelial cell (ec) exhibits numerous Weibel-Palade bodies (WP) and plasmalemmal vesicles (v), often fused (fv). In the subendothelium, collagen bundles (arrowheads) and elastin (e) are present. Inset: high magnification of a Weibel-Palade body showing the cross-sectioned tubular inclusions. 1: lumen; ly: lysosome. (Internal scale bar $=0.320 \mu \mathrm{m}$; and for inset $=0.140 \mu \mathrm{m}$ ).

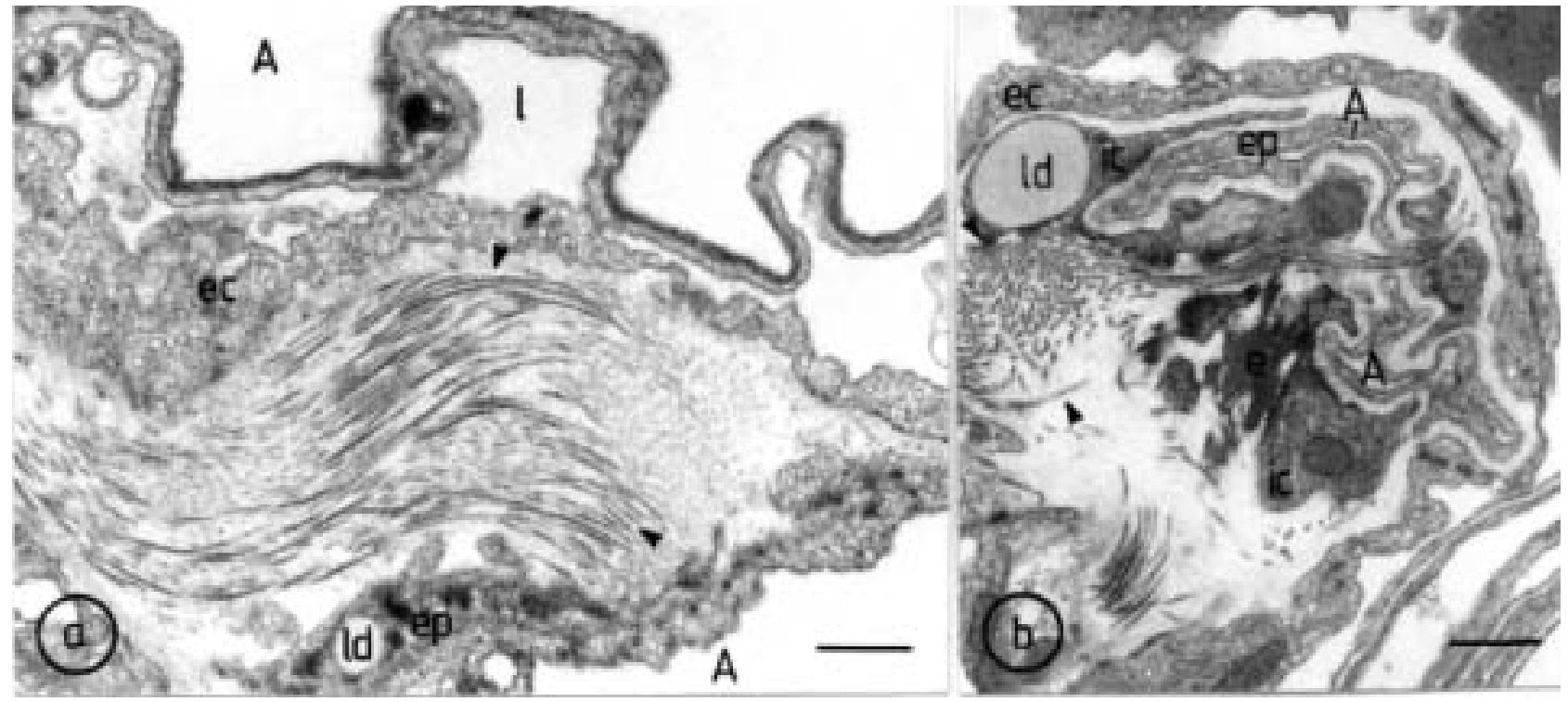

Fig. 4. - Lung interstitium of a 24 week old diabetic animal. a) The expanded interstitium is characterized by frequent collagen bundles (arrowheads) that appear cut longitudinally or transversally. (Internal scale bar $=0.220 \mu \mathrm{m}$ ). b) In the apparently enlarged interstitium, the interstitial cells (ic) contain lipid droplets (ld). 1: capillary lumen; ec: endothelial cell; A: alveolar space; ep: type I epithelial cell; e: elastin (Internal scale bar $=0.310 \mu \mathrm{m})$. 


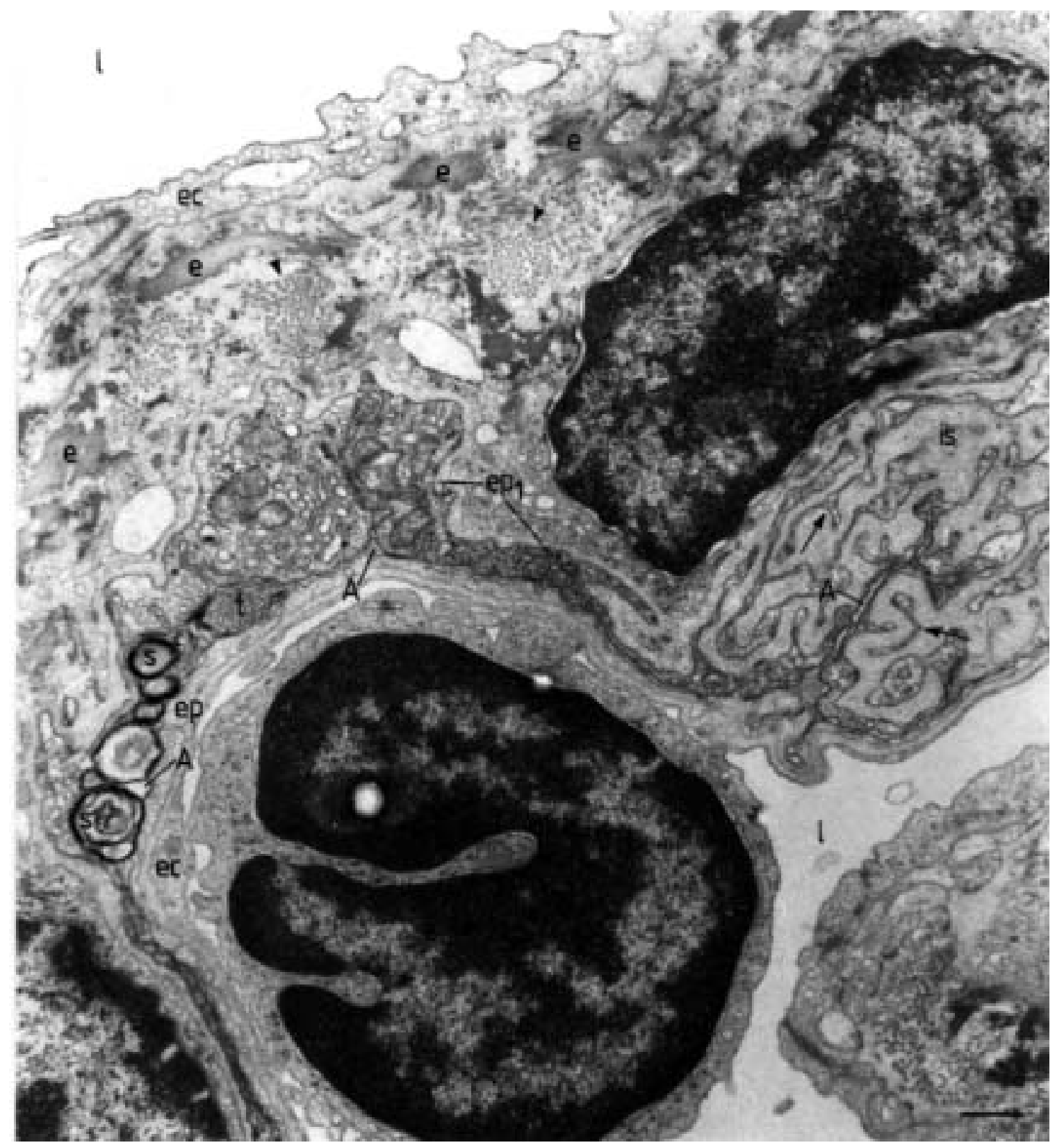

Fig. 5. - Compressed lung alveolar space of a 24 week old diabetic hamster. Over a large surface, the alveolar space (A) becomes collapsed, displaying compressed surfactant, which appears as tubular myelin $(\mathrm{t})$ or as a multilayered structure (s). Note the osmiophilic type I epithelial cell ( $\mathrm{ep}_{1}$ ), whose contorted contour (arrows) is accompanied by interstitial tissue (is), as well as the presence of apparently frequent collagen bundles (arrowheads), and elastin (e). 1: vascular lumen; ec: endothelial cell; ep: type I epithelial cell. (Internal scale bar=0.430 $\mu \mathrm{m}$ ).

previous studies on micro- and macrovascular chan-ges that take place in diabetic and hyperlipidaemic hamsters [24].

One special characteristic was the decreased labelling and patchy distribution of CF-detectable anionic sites of the endothelial plasmalemma in lung capillaries and venules both of D and HD group hamsters. This modification appeared soon after the induction of disease, and is analogous with that reported for diabetic arterial endothelium [25], myocardial and retinal capillary endothelium [24], and endocardium [26]. The lack of a continuous anionic charge on the luminal surface of the endothelial cells may impede the relationship of the latter with the circulating blood cells (that also have a net negative charged surface), as well as with the circulat- ing plasma macromolecules. This may account for several functional abnormalities that are ascribed to the diabetic lung.

The endothelial cells were rich in cytoskeletal elements, and displayed numerous fused plasmalemmal vesicles, a feature that was also reported for endocardial endothelium in diabetes [26]. The fused plasmalemmal vesicles may represent an additional route for transendothelial transport, and could explain the increased permeability for water, electrolytes and plasma molecules, known to occur in diabetes. The large number of copies of Weibel-Palade bodies detected in the lung venular endothelium may account for the reported elevation of plasma concentration of von Willebrand factor in diabetes [27]. 


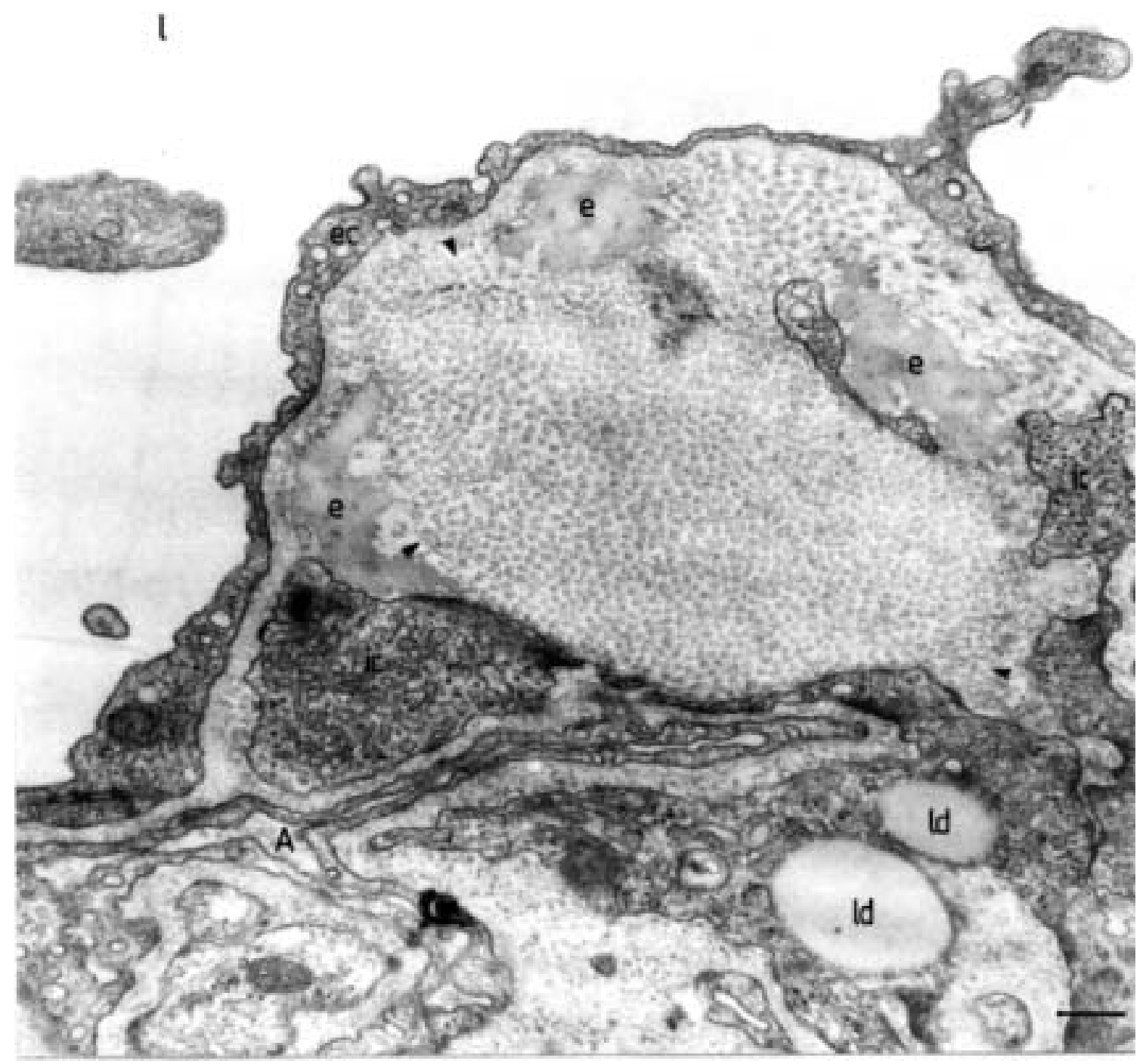

Fig. 6. - Lung fragment of a hamster after 18 weeks of combined diabetes and hyperlipidaemia. Note the collapsed alveolar space (A), the enlarged interstitium rich in elastin (e) and collagen bundles (arrowheads), and the presence of interstitial cells (ic) containing lipid droplets (ld). 1: vascular lumen; ec: endothelial cell. (Internal scale bar=0.210 nm).

Interestingly, despite the extensive blood removal before tissue fixation, the diabetic hamster often displayed pulmonary intravascular macrophages (PIM) still adherent to the endothelium. Although PIMs have not been found in the vessels of normal hamsters, in diabetic animals their presence was common. This population of mature phagocytic cells was reported to occur in ruminants, pigs and cats [28], and is relevant for pulmonary inflammation and associated injury. The occurrence of intravascular macrophages in the diabetic lung could be correlated to inflammatory reactions, since recent data have shown that macrophage-derived cytokines were increased in the serum of patients with insulin-dependent diabetes mellitus [29].

Compared to the normal lung morphology [30], the examination and morphometric data of the hamsters lungs in diabetes, and diabetes associated with hyperlipidaemia showed that $\sim 35 \%$ of the capillaries and $\sim 30 \%$ of alveoli became narrowed and apparently compressed; this may be due, in part, to the pressure exerted by the hyperplasic perivascular extracellular matrix, epithelial extracellular matrix and interstitium. These modifications induce an increased thickness of the air-blood barrier, that may impede the gas transport, and could promote an uneven distribution of surfactant over the collapsed alveolar epithelial cells. These changes appear earlier and faster in diabetes associated with hyperlipidaemia, which indicates that hyperglycaemia and hyperlipidaemia have a cumulative effect.

To a certain extent, the structural changes observed in the pulmonary extracellular matrix of hamsters with diabetes or diabetes associated with hyperlipidaemia could be ascribed to the appearance of glycation of proteins in diabetic conditions [7], lung collagen being subjected to the Maillard reaction [31].

With the data so far obtained, we cannot ascertain whether the changes observed are reversible, as reported for some biochemical parameters in experimental hyperglycaemia that were corrected to basal conditions $[5,6,32]$.

Taken together, the results reported here provide the structural correlate of the functional and biochemical disturbances associated with diabetes. 
Acknowledgements: The authors are indebted for the excellent assistance of A. Hillebrand (animal models), M. Toader, M. Misici (experiments), E. Stefan (photographs), and M. Schean and C. Neacsu (graphics).

\section{References}

1. Sandler M, Bunn AE, Stewart RI. Cross-section study of pulmonary function in patients with insulin-dependent diabetes mellitus. Am Rev Respir Dis 1987; 135: 223-229.

2. Innocenti F, Fabbri A, Anichini R, et al. Indications of reduced pulmonary function in type I (insulin-dependent) diabetes mellitus. Diabetes Res Clin Pract 1994; 25: 161-168.

3. Russ RD, Tobin BW. Alteration of segmental vascular resistance in the pulmonary circulation of diabetic rats. Can J Physiol Pharmacol 1996; 74: 1010-1015.

4. Irizar A, Ioannides C. Extrahepatic expression of P450 proteins in insulin-dependent diabetes mellitus. Xenobiotica 1995; 25: 941-949.

5. Ofulue AF, Khadempour MH, Thurlbeck WM. Diminished levels of insulin-like growth factor-I in lungs in streptozotocin-induced diabetes: relation to nutritional status and growth. Exp Lung Res 1994; 20: 27-40.

6. Erman A, van Dyk DJ, Chen-Gal B, et al. Angiotensin converting enzyme activity in the serum, lung and kidney of diabetic rats. Eur J Clin Invest 1993; 23: 615-620.

7. Myint $\mathrm{T}$, Hoshi $\mathrm{S}$, Ookawara $\mathrm{T}$, et al. Immunological detection of glycated proteins in normal and streptozotocin-induced diabetic rats using anti-hexitol-lysine IgG. Biochim Biophys Acta 1995; 1272: 73-79.

8. Vracko R, Thorning D, Huang TW. Basal lamina of alveolar epithelium and capillaries: quantitative changes with aging and diabetes mellitus. Am Rev Respir Dis 1979; 120: 973-983.

9. Kida K, Utsuyama M, Takizawa T, et al. Changes in lung morphologic features and elasticity caused by streptozotocin-induced diabetes mellitus in growing rats. $\mathrm{Am}$ Rev Respir Dis 1983; 128: 125-131.

10. Crouch EC, Martin GR, Brody JS. Basement membranes. In: Crystal RG, West JB, Barens PJ, Weibel ER, eds. The Lung: Scientific Foundations. Philadelphia, New York, Lippincott-Raven Press, 1997; pp. 769-791.

11. Farina J, Furio V, Fernandez-Acenero MJ, et al. Nodular fibrosis of the lung in diabetes mellitus. Virchows Arch 1995; 427: 61-63.

12. Guttentag SH, Phelps DS, Stenzel W, et al. Surfactant protein A expression is delayed in fetuses of streptozotocin-treated rats. Am J Physiol 1992; 262: L489-L494.

13. Guttentag SH, Phelps DS, Warshaw JB, et al. Delayed hydrophobic surfactant protein (SP-B, SP-C) expression in fetuses of streptozotocin-treated rats. Am J Respir Cell Mol Biol 1992; 7: 190-197.

14. Colpaert C, Hogan J, Stark AR, et al. Increased muscularization of small pulmonary arteries in preterm infants of diabetic mothers: a morphometric study in noninflated, noninjected, routinely fixed lungs. Pediatr Pathol Lab Med 1995; 15: 689-705.

15. Moutschen MP, Scheen AJ, Lefebre PJ. Impaired immune responses in diabetes mellitus: analysis of the factors and mechanisms involved. Relevance to the increased susceptibility of diabetic patients to specific infections. Diabete Metab 1992; 18: 187-201.
16. Westphal SA, Sarosi GA. Diabetic ketoacidosis associated with pulmonary coccidioidomycosis. Clin Infect Dis 1994; 18: 974-978.

17. Thomas WA, O'Neal RM, Lee KT. Thromboembolism, pulmonary arteriosclerosis, and fatty meals: an experimental study of the effect of intermittent fatty meals on thromboembolic-induced pulmonary arteriosclerosis in rabbits. Arch Pathol 1956; 61: 380-389.

18. Heptinstall RH. Experimental pulmonary atheroma. $J$ Path Bact 1957; 77: 535-542.

19. Komuro K, Rosenzweig DY. Experimental production of pulmonary hypertension and pulmonary atherosclerosis in the rabbit. Circ Res 1967; 20: 545-551.

20. Gilligan JP, Langner RO. Effect of removal of atherogenic diet on protein synthesis and cholesterol retention in rabbit aorta and lung. Atherosclerosis 1985; 54: 1-10.

21. Bailey JM, Makheja AN, Lee R, et al. Systemic activation of 15-lipoxygenase in heart, lung and vascular tissues by hypercholesterolemia: relationship to lipoprotein oxidation and atherogenesis. Atherosclerosis 1995; 113: 247-258.

22. Ruan Y, Takahashi K, Naito M. Immunohistochemical detection of macrophage-derived foam cells and macrophage colony-stimulating factor in pulmonary atherogenesis of cholesterol-fed rabbits. Pathol Int 1995; 45: 185-195.

23. Williamson JR, Rowold E, Hoffman P, et al. Influence of fixation and morphometric techniques on capillary basement membrane thickening. Prevalence data in diabetes. Diabetes 1976; 25: 604-613.

24. Simionescu M, Popov D, Sima A, et al. Pathobiochemistry of combined diabetes and atherosclerosis studied on a novel animal model: the hyperlipidemic-hyperglycemic hamster. Am J Pathol 1996; 148: 997-1014.

25. Raz I, Havivi Y, Yarom R. Reduced negative surface charge on arterial endothelium of diabetic rats. Diabetologia 1988; 31: 618-620.

26. Popov D, Sima A, Stern D, et al. The pathomorphological alterations of endocardial endothelium in experimental diabetes, and diabetes associated with hyperlipidemia. Acta Diabetol 1996; 33: 41-47.

27. Katayama M, Hirai S, Kato I, et al. Immunoenzymometric analysis for plasma von Willebrand factor degradation in diabetes mellitus using monoclonal antibodies recognizing protease-sensitive sites. Clin Biochem 1994; 27: 123-131.

28. Warner AE, Brain JD. The cell biology and pathogenic role of pulmonary intravascular macrophages. Am J Physiol 1990; 258: L1-L12.

29. Hussain MJ, Peakman M, Gallati H, et al. Elevated serum levels of macrophage-derived cytokines precede and accompany the onset of IDDM. Diabetologia 1996; 39: 60-69.

30. Simionescu M. Cellular organization of the alveolarcapillary unit: structural-functional correlations. In: Said SI, ed. The Pulmonary Circulation and Acute Lung Injury. 2nd Edn. Mount Kisco, NY, Futura Publishing Co. Inc., 1991; pp. 13-42.

31. Bellmunt MJ, Portero M, Pamplona R, et al. Evidence for the Maillard reaction in rat lung collagen and its relationship with solubility and age. Biochim Biophys Acta 1995; 1272: 53-60.

32. Stevens EJ, Willars GB, Lindbury P, et al. Vasoreactivity and prostacyclin release in streptozotocin-diabetic rats: effects of insulin or aldose reductase inhibition. $\mathrm{Br} J$ Pharmacol 1993; 109: 980-986. 